\title{
Sistem Informasi Penjualan Pada TB Harmonis Menggunakan Metode FAST
}

\author{
R.M. Nasrul Halim \\ Program Studi Teknik Informatika, Fakultas Ilmu Komputer \\ Universitas Bina Darma \\ Palembang, Indonesia \\ e-mail: nasrul.halim@binadarma.ac.id
}

\begin{abstract}
The development of computerized technology requires many parties to compete in using a computerized system to improve the performance and effectiveness of a company or agency. Likewise with the Harmonis Bookstore (TB) which so far is still using the manual method in its sales system. This can affect performance and company profits. Overcoming this matter, TB Harmonis created a desktop-based computerized sales information system so that it can improve company performance to be fast, accurate and can do data processing on a large scale which can affect profit and can compete with other similar companies. The system development method in this study uses Framework for the Application of System Thinking (FAST) method. FAST is a combination of several systems development methods consisting of 7 phase of development. Modeling the system using UML consisting of use case diagrams, activity diagrams and class diagrams. The results of this study are book sales information systems which can improve the performance, effectiveness and efficiency of Harmonis TB Palembang.
\end{abstract}

Keywords—information system, FAST, UML

\begin{abstract}
Abstrak-Berkembangnya teknologi komputerisasi menuntut banyak pihak untuk berlomba-lomba menggunakan sistem terkomputerisasi agar dapat meningkatkan kinerja dan efektifitas suatu perusahaan atau instansi. Begitu juga dengan Toko Buku (TB) Harmonis yang selama ini masih menggunakan cara manual dalam sistem penjualannya. Hal tersebut dapat mempengaruhi kinerja dan keuntungan perusahaan. Mengatasi hal tersebut maka TB Harmonis membuat sebuah sistem informasi penjualan yang terkomputerisasi berbasis desktop sehingga dapat meningkatkan kinerja perusahaan menjadi cepat, akurat dan dapat melakukan pengolahan data dalam skala besar yang dapat berpengaruh terhadap keuntungan serta dapat bersaing dengan perusahaan lain yang sejenis. Metode pengembangan sistem dalam penelitian ini menggunakan metode Framework for the Application of System Thinking (FAST). FAST merupakan gabungan dari beberapa metode pengembangan sistem yang terdiri dari 7 tahapan pengembangan. Pemodelan sistem menggunakan UML yang terdiri dari use case diagram, activity diagram dan class diagram. Hasil dari penelitian ini berupa sistem informasi penjualan buku yang dapat meningkatkan kinerja, efektifitas dan efisiensi TB Harmonis Palembang.
\end{abstract}

Kata Kunci-sistem informasi, FAST, UML

\section{PENDAHULUAN}

Semakin ketatnya persaingan bisnis dalam perkembangan Teknologi Informasi yang semakin maju, pengolahan data dan informasi secara digital dan terkomputerisasi menjadi suatu hal yang sangat penting dan harus segera diikuti. Hal itu disebabkan karena sistem pengolahan data secara komputerisasi dapat memberikan manfaat yang besar bagi kinerja dan keberadaan perusahaan ataupun badan usaha lainnya. Sistem informasi secara komputerisasi memberikan banyak kelebihan dan manfaat, antara lain sistem pengolahan data yang dapat dilakukan secara cepat, akurat dan dapat dilakukan terhadap pengolahan data dalam skala besar, proses pencarian data secara cepat. Dengan adanya sistem yang terkomputerisasi proses pengolahan, penyimpanan dan pencarian data dapat dilakukan lebih cepat sehingga dapat meningkatkan kinerja yang lebih efektif dan efisien. Sistem informasi secara komputerisasi dapat diterapkan disemua bidang, diantaranya pada bidang bisnis penjualan buku. Salah satu perusahaan yang bergerak dibidang penjualan buku di kota Palembang adalah Toko Buku (TB) Harmonis.

TB Harmonis merupakan menjual berbagai jenis buku, baik buku pelajaran mulai dari tingkat TK sampai dengan tingkat perguruan tinggi serta buku-buku bacaan umum lainnya. Meskipun sudah menjadi TB yang cukup besar, namun sistem penjualan pada TB Harmonis saat ini belum menggunakan sistem penjualan yang terkomputerisasi, artinya TB Harmomnis masih menerapkan sistem manual sederhana. Sistem penjualan dilakukan dengan cara pencatatan ke buku besar. Hal ini tentu saja memiliki banyak sekali kelemahan, antara lain terjadinya duplikasi data penjualan, kemudian datadata penjualan dalam bentuk kertas sangat mudah rusak atau hilang dikarenakan tercecer dan lain sebagainya, sehingga berpengaruh terhadap pembuatan laporan penjualan. Permasalahan tersebut dapat mengakibatkan keterlambatan pembuatan laporan baik bulanan maupun tahunan. Selain itu juga permasalahan yang dihadapi adalah sulitnya melakukan pencarian stok buku apakah masih tersedia atau sudah habis, sehingga harus melakukan pencarian secara langsung ke lokasi buku. Hal tersebut tentu saja dapat merugikan waktu, baik waktu penjual maupun waktu pembeli.

Mengatasi permasalahan tersebut, TB Harmonis menerapkan sistem penjualan yang terkomputerisasi, dalam bentuk sistem informasi penjualan buku sehingga semua 
permasalahan dapat teratasi. Sistem informasi "adalah sekumpulan dari komponen-komponen suatu organisasi mengenai proses pembuatan dan arus informasi. Sistem informasi adalah rangkaian berbagai komponen seperti manusia, data, prosedur dan teknologi yang terhubung satu sama lain untuk menghasilkan informasi yang bernilai dalam proses pengambilan keputusan"[1]. Sistem informasi "merupakan kombinasi yang teratur baik dari orang-orang, perangkat keras, perangkat lunak, jaringan kompunikasi, dan basis data yang mengumpulkan, mengedit, dan menyebarkan suatu informasi dalam suatu organisasi'[2]. Manfaat yang dapat diperoleh dengan menggunakan Sistem Informasi berbasis komputer "adalah untuk mendapatkan informasi yang berkualitas, akurat dan efektif”'[3].

Penelitian ini bertujuan untuk membangun sistem informasi penjualan pada TB Harmonis sehingga tidak ada lagi duplikasi data dan tidak ada lagi data-data yang rusak atau tercecer sehingga pembuatan laporan dapat dilakukan lebih cepat dan akurat. Proses pencarian buku juga dapat dilakukan lebih cepat, sehingga proses penjualan dapat lebih efektif dan efisien.

Sistem informasi penjualan ini dibangun berbasis desktop menggunakan metode Framework for the Application of System Thinking (FAST). Metode FAST merupakan gabungan dari beberapa metode pengembangan sistem yang dikemas dalam suatu kerangka kerja yang fleksibel untuk berbagai proyek. Metode ini memiliki banyak kelebihan antara lain kemampuan untuk mendukung pengembangan aplikasi yang baik serta didukung oleh teknik yang lain.

FAST "adalah kerangka kerja yang fleksibel dalam menyediakan berbagai jenis proyek maupun strategi yang berbeda serta merupakan gabungan dari berbagai penggunaan metode pengembangan sistem yang sering dijumpai dalam banyak referensi metode pengembangan sistem" [4]. Metode pengembangan sistem FAST (Framework for the Application System Thinking) "terdiri dari fase-fase Scope Definition, Problem Analysis, Requirements Analysis, Logical Design dan Physical Design"[5].

\section{METODOLOGI PENELITIAN}

\section{A. Metode Pengembangan Sistem}

Metode FAST merupakan metode pengembangan sistem yang digunakan dalam penelitian ini. Metode FAST adalah metode pengembangan sistem yang merupakan gabungan beberapa metode pengembangan sistem yang banyak digunakan yang disajikan dalam suatu kerangka kerja yang fleksibel yang dapat dikembangkan dengan metode lainnya. FAST "merupakan metode pengembangan sistem yang dapat menghasilkan sebuah sistem dalam waktu singkat dengan kualitas yang baik. Metode ini lebih fleksibel karena dapat dikembangkan dengan metode lain yang sedang berkembang seperti metode yang berorientasi objek. Metode FAST terdiri dari tahapan: Scope definition, problem analysis, requirements analysis, logical design, decision analysis, physical design and integration, construction and testing dan instalation and delivery"[6].
Penelitian ini menggunakan tujuh tahapan dari metode FAST yaitu:

1) Definisi Ruang Lingkup (Scope Definition). Tahapan ini peneliti mendefinisikan ruang lingkup permasalahan dan tujuan dari pembangunan sistem informasi serta menentukan batasan-batasan dari sistem yang dibangun.

2) Analisis Masalah (Problem Analysis). Tahapan ini peneliti mempelajari sistem yang berjalan kemudian menanalisis untuk mencari dan menemukan permasalahan yang terjadi sebagai bahan untuk pengembangan sistem.

3) Analisis Kebutuhan (Requirement Analysis). Tahapan ini peneliti menganalisis kebutuhan apa saja yang dibutuhkan dalam sistem, baik kebutuhan fungsional maupun kebutuhan non fungsional

4) Desain Logis (Logical Desain). Tahapan ini merancang kebutuhan dan memodelkan sistem menggunakan beberapa diagram UML (Unified Modelling Language).

5) Analisis Keputusan (Decision Analysis). Tahapan ini menentukan perangkat lunak dan perangkat keras apa saja yang diterapkan ke dalam sistem yang dibuat.

6) Desain Fisik (Physical Desain). Tahapan ini merupakan tahapan perancangan antarmuka sistem dan database.

7) Kontruksi dan Pengujian (Construction and Testing). Setelah sistem yang dibangun telah selesai, selanjutnya adalah tahapan pembangunan sistem untuk selanjutnya dilakukan pengujian terhadap sistem yang dibuat.

\section{B. Pemodelan Sistem}

Pemodelan sistem menggunakan Unified modelling language (UML) yang merupakan alat bantu dalam menggambarkan dan mendokumentasikan suatu perangkat lunak sistem berorientasi objek yang disajikan dalam bentuk gambar atau diagram.

UML "merupakan sebuah bahasa yang menjadi standar dalam industri untuk visualisasi perancangan dan pendukumentasian sistem perangkat lunak. Bahasa pemodelan ini dapat digunakan untuk membuat model dari semua aplikasi perangkat lunak, dimana aplikasi tersebut dapat dijalankan pada perangkat keras sistem operasi dan jaringan apapun, dan dapat ditulis menggunakan bahasa pemograman apapun"[7]. UML "merupakan bahasa pemodelan berupa gambar atau grafik untuk menggambarkan, menspesifikasikan, membangun dan mendokumentasikan sebuah sistem berbasis object oriented'[8].

UML versi 2 terdiri dari tiga kategori dan memiliki 13 jenis diagram "yaitu: 1) Structure Diagram, terdiri dari Class diagram, Object diagram, Component diagram, Deployment diagram, Composite structure diagram, Package diagram, 2) Behavior Diagram, terdiri dari Use case diagram, Activity diagram, State Machine diagram, 3) Interaction diagram, 
terdiri dari Communication diagram, Interaction Overview diagram, Sequence diagram, Timing diagram" [9]. Diagram yang digunakan dalam pemodelan sistem ini adalah Use Case diagram, Activity Diagram dan Class Diagram.

\section{HASIL DAN PEMBAHASAN}

\section{A. Definisi Ruang Lingkup}

Tahapan pendefinisian ruang lingkup merupakan tahapan awal dalam pembangunan sistem informasi penjualan buku pada TB Harmonis menggunakan metode FAST. Ruang lingkup penelitian ini meliputi: pengelolaan data buku, pengelolaan data penjualan serta pembuatan laporan data stok dan laporan data penjualan buku.

\section{B. Analisis Masalah}

Permasalahan yang dihadapi TB Harmonis saat ini TB Harmonis masih menerapkan sistem penjualan manual sederhana. Hal ini tentu saja memiliki banyak sekali kekurangan, antara lain:

1) Sistem penjualan dilakukan dengan cara pencatatan ke buku besar membutuhkan waktu yang cukup lama terutama dalam hal pencarian data stok buku yang masih tersedia.

2) Data yang disimpan dapat menyebabkan terjadinya duplikasi data penjualan karena informasi yang tidak akurat dan tidak terorganisir dengan baik.

3) Penggunaan buku/ kertas yang berlebihan untuk proses dokumentasi menyebabkan biaya yang cukup tinggi.

4) Sistem pencatatan manual yang dilakukan dapat menyebabkan kesalahan dalam proses input data selain itu dapat menyebabkan data-data penjualan dalam bentuk kertas sangat mudah rusak atau hilang dikarenakan tercecer dan lain sebagainya.

5) Proses pembuatan laporan baik bulanan maupun tahunan memakan waktu yang lama karena harsu membuka catatan penjualan dalam buku besar.

6) Sulitnya melakukan pencarian stok buku apakah masih tersedia atau sudah habis, sehingga harus melakukan pencarian secara langsung ke lokasi buku, hal tersebut tentu saja dapat merugikan waktu, baik waktu penjual maupun waktu pembeli.

\section{Analisis Kebutuhan}

Kebutuhan sistem dalam penelitian ini meliputi:

\section{1) Kebutuhan Fungsional}

Kebutuhan fungsional yang terdapat dalam sistem adalah sistem informasi harus sistem dapat mengelola data buku, mengelola data transaksi penjualan dan pembelian. Selain itu sistem dapat melakukan penyimpanan secara rapi sehingga mudah dalam pencarian data. Sistem dapat menghasilkan laporan penjualan dalam bentuk laporan dan grafik penjualan.

\section{2) Kebutuhan Non-fungsional}

Kebutuhan non fungsional yang harus terpenuhi adalah sistem harus mudah digunakan dan adanya bentuk pelatihan bagi penggunanya.

\section{Desain Logis}

Tahapan ini merupakan tahapan pemodelan sistem menggunakan diagram UML. Diagram UML yang digunakan adalah Use Case diagram, Activity Diagram dan Class Diagram. Pemodelan sistem dalam bentuk diagram use case dapat dilihat pada Gambar 1.

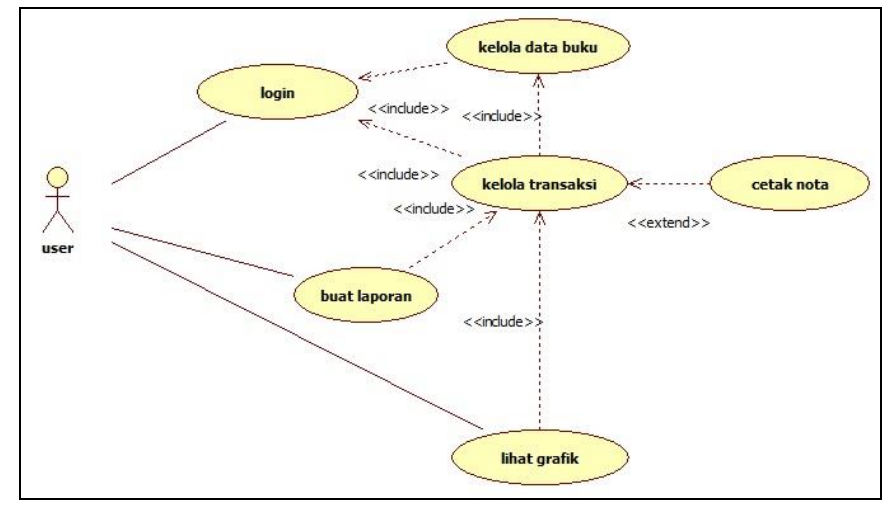

Gambar 1. Use case diagram sistem

Berdasarkan Gambar 1 dapat dilihat bahwa sistem ini hanya terdiri dari satu aktor yaitu user. User dalam sistem ini harus melakukan login untuk dapat mengolah data buku dan mengelola data transaksi. Untuk membuat laporan, user dapat langsung membuatnya tanpa harus melakukan login. Selanjutnya activity diagram user dapat dilihat pada Gambar 2.

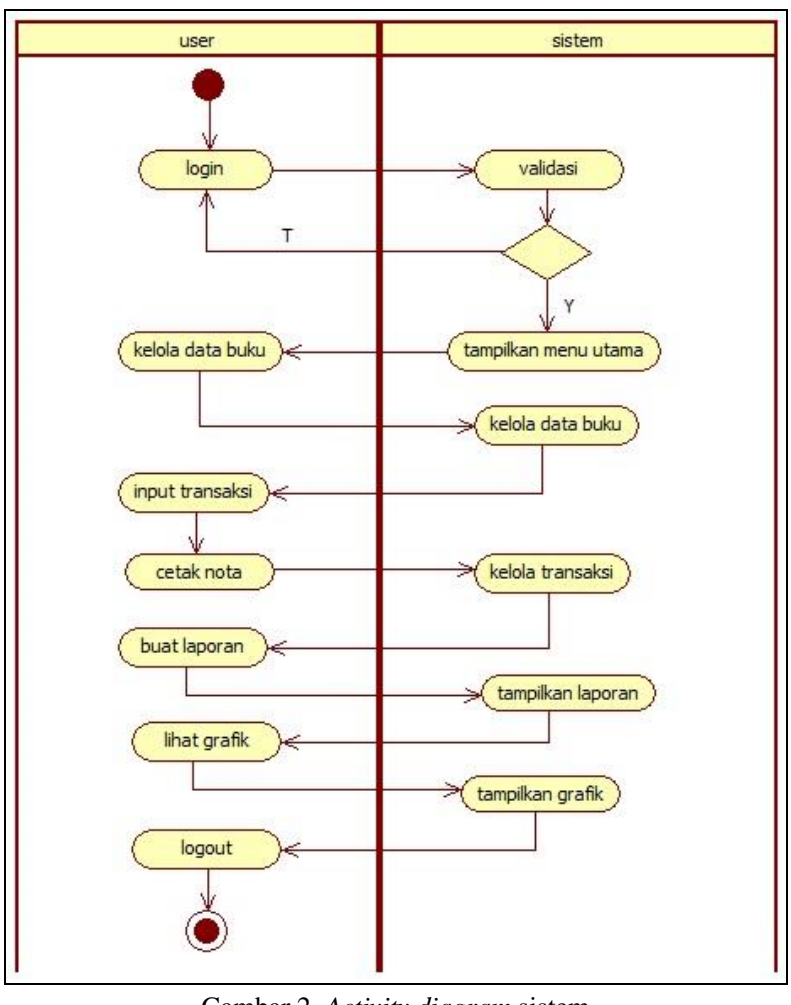


Berdasarkan Activity diagram pada Gambar 2 dapat dilihat bahwa untuk menggunakan sistem, user terlebih dahulu melakukan login agar dapat menggunakan sistem antara lain mengelola data buku, data transaksi, membuat laporan penjualan dan melihat grafik penjualan

Selanjutnya class diagram sistem dapat dilihat pada Gambar 3, yang terdiri dari 4 buah class, yaitu class buku, class transaksi, class laporan dan class grafik. Masing-masing class terdiri dari fungsi-fungsi yang disesuaikan dengan kebutuhannya.

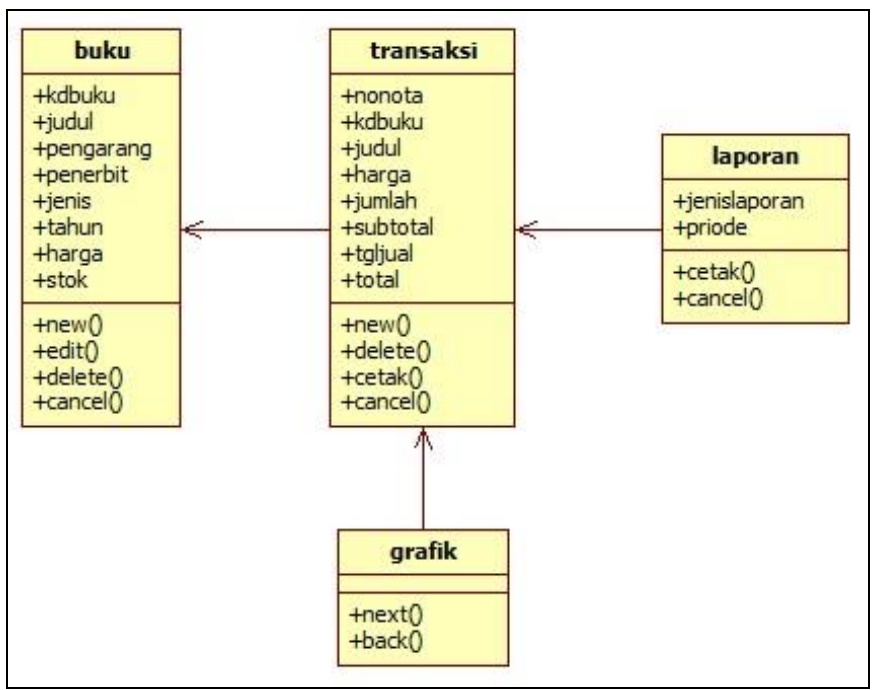

Gambar 3. Class diagram sistem

\section{E. Anallisis Keputusan}

Berdasarkan hasil rancangan sistem yang sudah dibuat, selanjutnya sistem dibangun dengan sarana dan prasarana berupa spesifikasi perangkat keras dan perangkat lunak sistem.

1) Spesifikasi perangkat keras
a) Processor intel dual core $2.1 \mathrm{GHz}$ atau lebih
b) RAM 2GB atau lebih
c) 250GB HDD atau lebih
d) Mouse dan keyboard
2) Spesifikasi perangkat lunak
a) OS Windows 7 atau lebih
b) Program Delphi 2007 atau lebih
c) Database MySQL

\section{F. Desain Fisik}

Tahapan FAST selanjutnya adalah tahapan desain fisik. Pada tahapan ini dibuat desain antarmuka sistem. Desain antarmuka tersebut antara lain:

\section{1) Menu Utama Sistem}

Tampilan menu utama sistem dapat dilihat pada Gambar 4, dimana menu utama terdiri dari menu login agar dapat melakukan pengolahan data buku, menu data buku untuk mengolah data buku, menu transaksi untuk melakukan transaksi penjualan, menu laporan untuk membuat laporan, menu grafik untuk melihat grafik penjualan menu help dan menu keluar sistem.

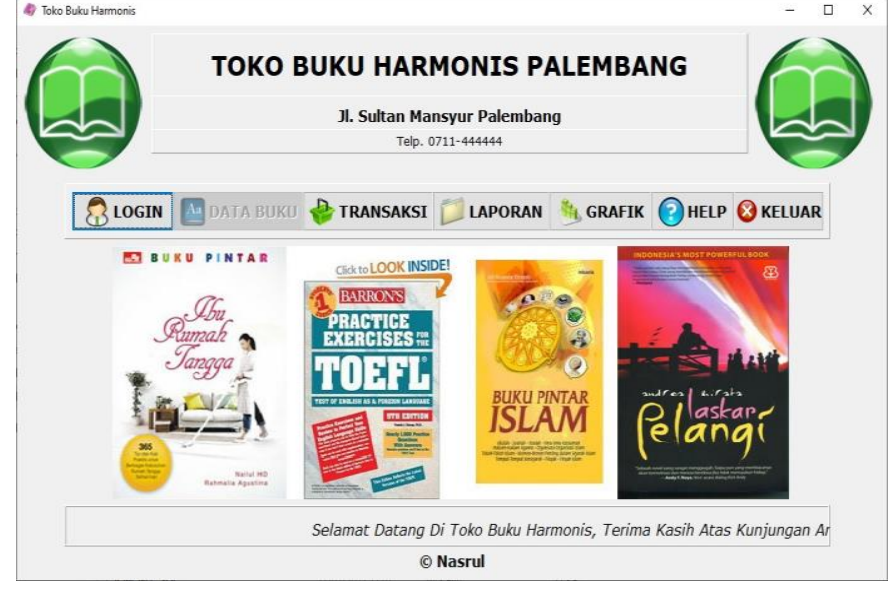

Gambar 4. Menu utama sistem

\section{2) Pengolahan Data Buku}

Halaman pengolahan data buku seperti pada Gambar 5 berfungsi untuk proses menambahkan data buku, mengedit data dan menghapus data buku yang hanya dapat dilakukan dengan login terlebih dulu, serta dapat melakukan proses pencarian data buku secara cepat berdasarkan kriteria jenis buku.

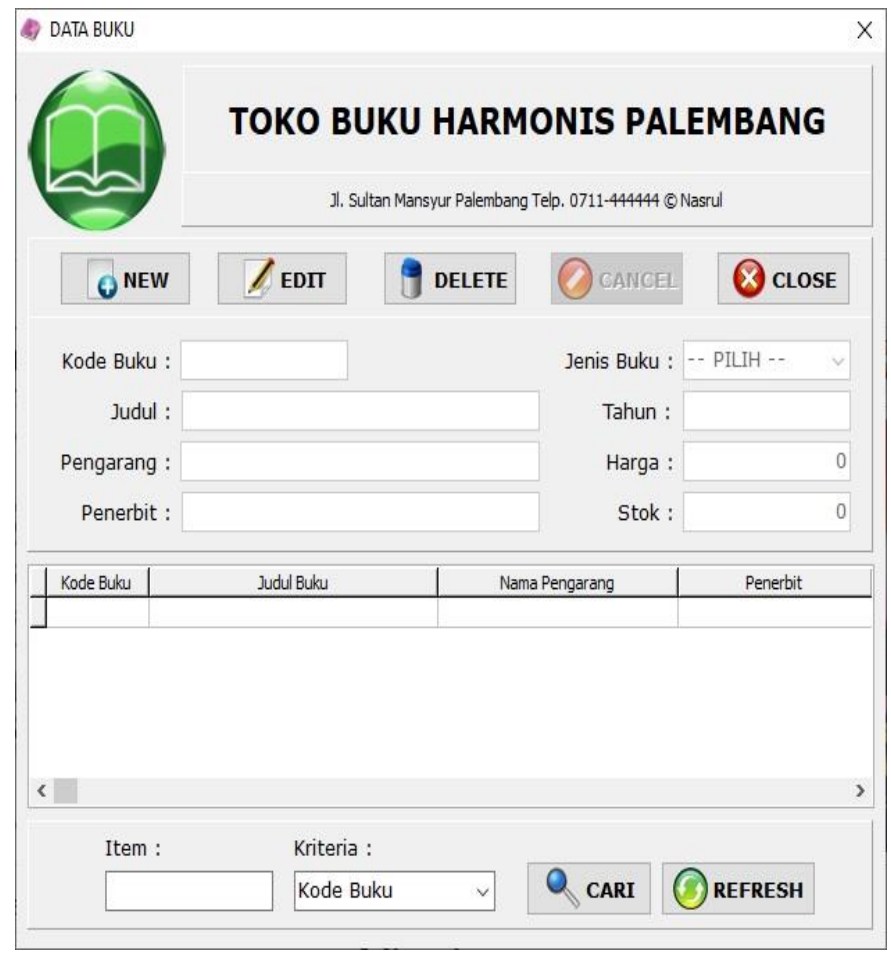

Gambar 5. Halaman pengolahan data buku

\section{3) Pengolahan Data Transaksi}

Untuk melakukan transaksi penjualan dapat dilakukan dengan membuka halaman transaksi penjualan seperti pada Gambar 6. Seluruh transaksi penjualan akan tercatan dan tersimpan ke dalam database. Setelah selesai transaksi dilanjutkan dengan mencetak nota. 


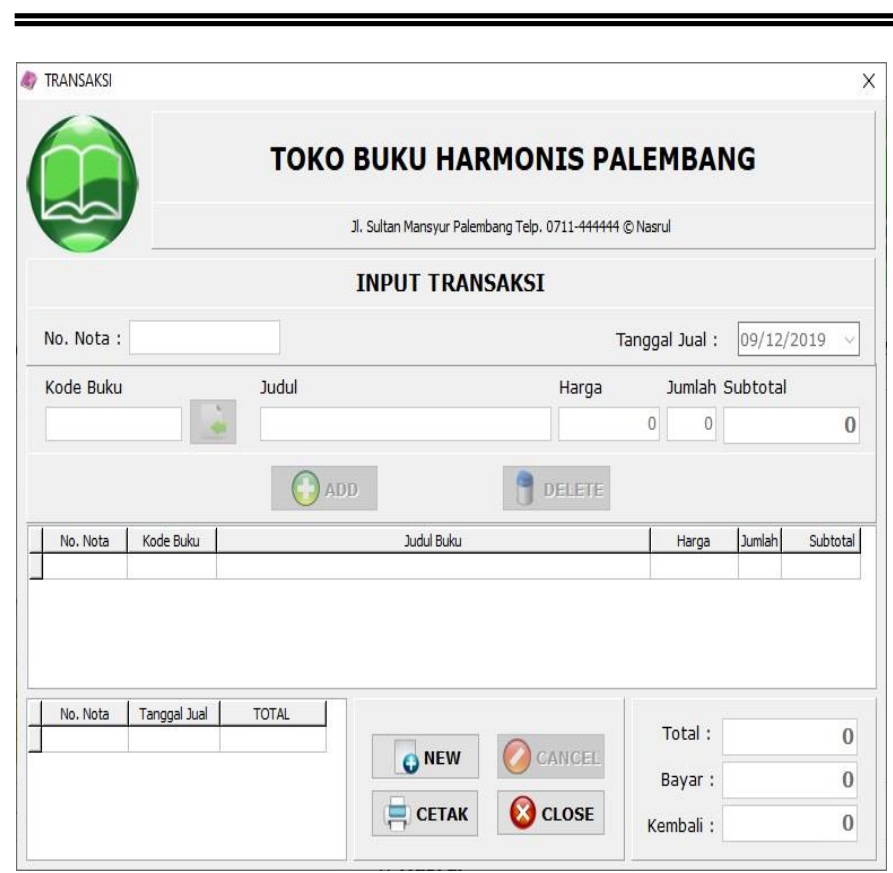

Gambar 6. Halaman pengolahan transaksi penjualan

\section{4) Cetak Laporan}

Untuk mencetak laporan dapat memilih jenis laporan yaitu laporan data buku dan laporan data transaksi penjualan berdasarkan rentang tanggal laporan yang ingin dicetak perminggu, perbulan ataupun pertahun yang dapat dilihat pada Gambar 7.

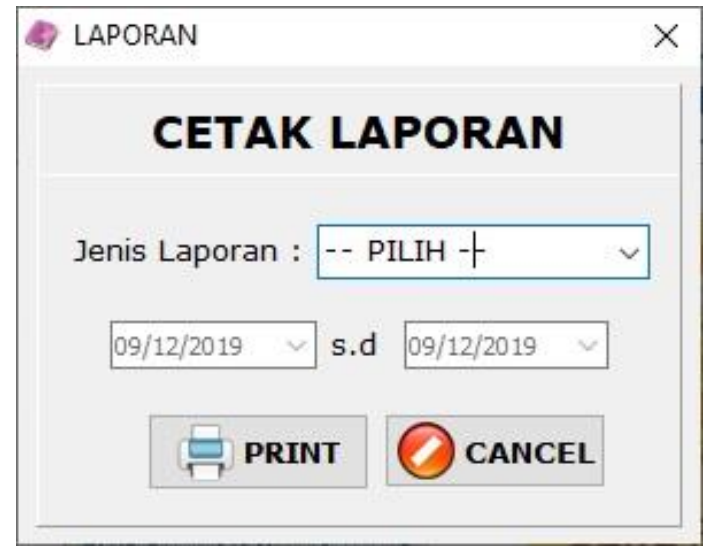

Gambar 7. Halaman cetak laporan

\section{F. Kontruksi dan Pengujian}

Tahapan akhir dalam penelitian ini adalah tahapan konstruksi dan pengujian. Tahapan kontruksi dengan menerapkan kode-kode program ke dalam bahasa pemrograman serta menghubungkan antara aplikasi dengan database. Setelah selesai selanjutnya akan dilakukan pengujian terhadap sistem yang dibuat. Pengujian dilakukan dengan menggunakan metode Black Box Testing.

Pengujian blackbox "merupakan pengujian terhadap fungsional aplikasi”[10]. Hasil pengujian dapat dilihat pada Tabel 1.
TABEL 1. HASIL PENGUJIAN

\begin{tabular}{|c|l|c|c|}
\hline \multirow{2}{*}{ No. } & \multicolumn{3}{|c|}{ Pengujian } \\
\cline { 2 - 4 } & \multicolumn{1}{|c|}{ Skenario Pengujian } & Komponen & Hasil \\
\hline 1 & $\begin{array}{l}\text { Login user dengan } \\
\text { memasukkan username dan } \\
\text { password }\end{array}$ & Form login & Diterima \\
\hline 2 & $\begin{array}{l}\text { Tambah data buku, edit, hapus } \\
\text { dan pencarian data buku }\end{array}$ & $\begin{array}{c}\text { Form data } \\
\text { buku }\end{array}$ & Diterima \\
\hline 3 & $\begin{array}{l}\text { Tambah data transaksi, hapus } \\
\text { dan cetak nota }\end{array}$ & $\begin{array}{l}\text { Form } \\
\text { transaksi }\end{array}$ & Diterima \\
\hline 4 & $\begin{array}{l}\text { Cetak laporan berdasarkan } \\
\text { tanggal }\end{array}$ & $\begin{array}{c}\text { Form cetak } \\
\text { laporan }\end{array}$ & Diterima \\
\hline
\end{tabular}

\section{KESIMPULAN}

Penelitian ini menghasilkan sebuah sistem informasi penjualan buku pada TB Harmonis berbasis desktop dengan mengikuti tahapan dari metode FAST (Framework for the Application of System Thinking). Sistem informasi ini dapat meningkatkan kinerja, efektifitas dan efisiensi TB Harmonis Palembang. dengan adanya sistem informasi ini proses transaksi penjualan menjadi lebih cepat, efektif dan efisien, serta proses pembuatan laporan dapat dibuat lebih cepat.

Untuk pengembangan selanjutnya Sistem informasi ini dapat dikembangkan menjadi sistem informasi berbasis web atau android dan dapat ditambahkan dengan fitur-fitur dan tampilan yang lebih menarik.

\section{DAFTAR PUSTAKA}

[1] A. Prasetyo and R. Susanti, "Sistem Informasi Penjualan Berbasis Web Pada PT. Cahaya Sejahtera Sentosa Blitar," J. Ilm. Teknol. Inf. Asia, vol. 10, no. 2, pp. 1-16, 2016.

[2] A. Anisah, "Desain Sistem Informasi Administrasi Bimbingan Konseling pada SMA Negeri 1 Tempilang dengan Model Fast," $J$. Sisfokom (Sistem Inf. dan Komputer), vol. 8, no. 1, pp. 92-97, 2019.

[3] R. M. N. Halim and R. Novrianda, "Sistem Pengolahan Data Kartu Pelajar Siswa SMA Negeri 1 Indralaya," Teknomatika, vol. 10, no. 1, pp. 1-9, 2017.

[4] A. R. Adiguna, "Analisis Dan Perancangan Sistem Informasi Manajemen Gudang Pada PT. Mitra Pinasthika Mulia Surabaya." Universitas Brawijaya, 2015.

[5] A. O. Sari and E. Nuari, "Rancang Bangun Sistem Informasi Persediaan Barang Berbasis Web Dengan Metode Fast (Framework For The Applications)," J. PILAR Nusa Mandiri, vol. 13, no. 2, pp. 261266, 2017.

[6] E. Yanuarti and S. Sarwindah, "Pengembangan Sistem Informasi Kebencanaan Menggunakan Metodologi FAST," Konf. Nas. Sist. Inf. 2018, 2018.

[7] R. R. C. Putra, "Aplikasi Peminjaman Ruangan Rapat Kantor Gubernur Provinsi Kepulauan Bangka Belitung Berbasis Android," J. Sisfokom (Sistem Inf. dan Komputer), vol. 8, no. 2, pp. 191-198, 2019.

[8] Z. Syahputra, "Penerapan Pemodelan UML Sistem Informasi Perpustakaan Pada Universitas Islam Indragiri Berbasis Client Server," SISTEMASI, vol. 4, no. 1, pp. 57-64, 2018.

[9] H. Hasdiana and H. Fahmi, "Aplikasi Pembelajaran Unified Modeling Language Berbasis Computer Assisted Instruction," Query J. Inf. Syst., vol. 2, no. 2, 2018.

[10] N. A. O. Saputri and R. M. N. Halim, "Aplikasi Peta Titik Rawan Banjir di Kota Palembang," J. Teknol. Inf. dan Ilmu Komput., vol. 6, no. 4 , pp. $450-455,2019$. 